Chapter 6

\title{
Dopamine and Glutamate Interactions in ADHD: Implications for the Future Neuropharmacology of ADHD
}

\author{
Erin M. Miller, Theresa C. Thomas, \\ Greg A. Gerhardt and Paul E. A. Glaser \\ Additional information is available at the end of the chapter \\ http://dx.doi.org/10.5772/54207
}

\section{Introduction}

In this chapter, we will discuss the interactions between a neurotransmitter that has been heavily implicated in ADHD, dopamine, and a neurotransmitter just beginning to be investigated, glutamate. We will examine the literature to reveal how current treatments for ADHD affect these neurotransmitter levels in specific areas of the brain that are thought to be dysfunctional in ADHD. Additionally, we will detail new data on dopamine and glutamate dysfunction utilizing approaches that are capable of accurately measuring levels of these neurotransmitters in two separate rodent models of ADHD. Finally, we will speculate on the role that the dopamine-glutamate interaction will play in the future neuropharmacology of ADHD and how measuring these neurotransmitter levels in rodent models of ADHD may aid in furthering the future pharmacotherapy of ADHD.

Throughout the text, we will use ADHD (Attention-Deficit/Hyperactivity Disorder) without reference to the DSM-IV type, unless a specific reference pertains to combined, inattentive or hyperactive subtypes.

\section{ADHD and the link to neurochemistry}

When the Diagnostic and Statistical Manual of Mental Disorders (DSM-1) was first published in 1952, childhood psychiatric disorders were thought to be caused by environment and referred to as 'reactions' [1]. It wasn't until the DSM-2 was published in 1968 that ADHD 
began to be separated from general reactions and become its own diagnosis, referred to as the 'hyperkinetic reaction of childhood.' This reaction was characterized by a short attention span, hyperactivity, and restlessness [2], and in 1980, with the publication of the DSM-3, the ADHD diagnosis became more specific and was described as ADD (attention-deficit disorder) [3]; however, by this time, this disorder was already being treated with stimulant medications, a treatment still used to this day.

Stimulant medications were initially discovered to treat hyperactivity in the early 1900s when the psychiatrist Charles Bradley used amphetamines to treat children with headaches caused by pneumoencephalography and found it improved their school performance, social interactions and emotional responses. However, amphetamine as a treatment for ADHD was ignored until years later due to a variety of reasons [4]. In the 1950s, researchers were beginning to look for the underlying mechanisms causing behavioral problems and it was at this time that Bradley's discovery of amphetamine as a treatment for hyperactivity was uncovered and investigations into the mechanism of action of amphetamine began. The amphetamine formulation Bradley used in his patients was called Benzedrine, a racemic mixture of 50/50 d- and l-amphetamine, produced by the company Smith, Kline and French [4]. Treatment with this medication in a variety of experimental paradigms reduced hyperactivity [5]; however, of particular note is a study published in 1976 showing decreased hyperactivity when treated with amphetamine in rodents with dopamine depletion [6]. This was the first time that hyperactivity was linked to dopamine, but far from the last.

\subsection{Dopamine}

Dopamine, classified as a catecholamine neurotransmitter, is produced in the cells of the substantia nigra (SN, A9) and ventral tegmental area (VTA, A10) of the midbrain and project to numerous brain regions, including the prefrontal cortex (PFC), striatum and nucleus accumbens (NA, see Figure 1). Projections from the VTA to the NA are identified as the mesolimbic pathway, or the "reward pathway," because these dopamine projections are involved in rewarding behaviors, [7] firing when a reward is greater than expected or when a reward is anticipated [8-10]. Projections from the SN to the striatum are referred to as the nigrostriatal pathway and play a role in many aspects of motor control [11]. The mesocortical system consists of dopaminergic projections from the VTA to the PFC, and it is implicated in many cognitive functions including, but most certainly not limited to, attention and memory [11]. The mesocortical system will be the main focus in this chapter.

Dopamine is produced from tyrosine into 3,4-dihydroxyphenylalanine (DOPA) by the enzyme tyrosine hydroxylase. DOPA is then made into dopamine via DOPA-decarboxylase. Conversely, dopamine is broken down or converted by a number of mechanisms: 1) dopamine- $\beta$-hydroxylase converts dopamine into norepinephrine, 2) monoamine oxidase (MAO) converts dopamine into 3,4-dihydroxyphenylacetic acid (DOPAC), and 3) catechol-o-methyltransferase (COMT) catalyzes the formation of homovanillic acid (HVA). Dopamine- $\beta$-hydroxylase only exists in norepinephrine neurons and thus will not be a focus here; however, MAO exists on the outer mitochondrial membrane and is also thought to be in abundance extracellularly, and COMT is mostly present extracellularly and plays a major role in regu- 
lating dopamine neurotransmission, especially in the PFC [11]. The final and most important method in which dopamine is cleared from the synapse is via the dopamine transporter (DAT). The DAT primarily exists on the presynaptic neuron and can transport dopamine either into or out of the neuron, dependent upon the concentration gradient. It has been discovered that the removal of dopamine from the synapse is predominantly performed by the DAT and not metabolism or diffusion [12].

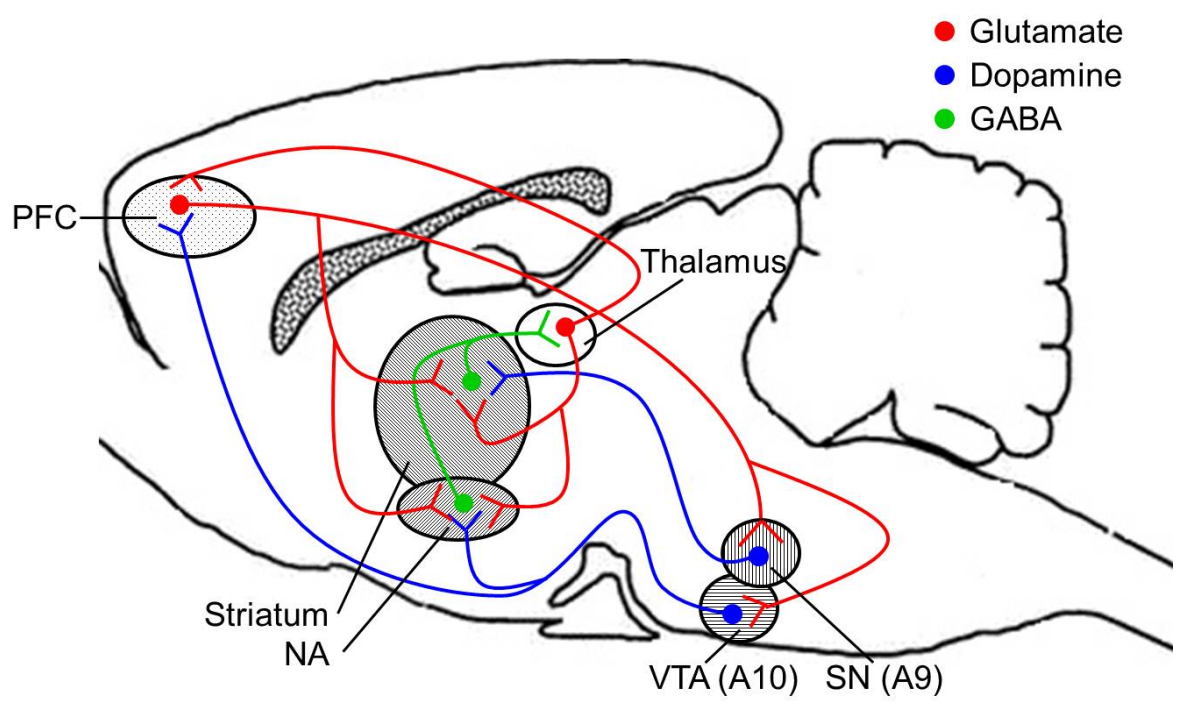

Figure 1. Modulatory dopaminergic neurons (blue) project to the dorsal striatum via the substantia nigra (SN, A9) and the ventral striatum and prefrontal cortex (PFC) via the ventral tegmental area (VTA, A10) in the rodent brain. From the striatum, inhibitory GABA neurons (green) extend to multiple regions including the thalamus, which has reciprocal excitatory glutamate connections (red) to the striatum, as well as connections to the PFC. Prefrontal cortical efferent excitatory glutamate neurons extend to the striatum, nucleus accumbens (NA), SN, as well as the VTA.

Intracellularly, dopamine is packaged into vesicles via the vesicular monoamine transporter (VMAT-2). The release of dopamine from the vesicle is $\mathrm{Ca}^{2+}$ and $\mathrm{Na}^{+}$dependent and occurs when an action potential raises the $\mathrm{Ca}^{2+}$ levels in the presynaptic neuron, causing vesicles stored with dopamine to bind to the cellular membrane and release their contents. The resulting synaptic dopamine is then able to bind to dopamine receptors on both the pre- and postsynaptic neurons. These receptors are classified into two major categories: 1) $\mathrm{D}_{1}$-type receptors, consisting of $\mathrm{D}_{1}$ and $\mathrm{D}_{5}$ and expressed postsynaptically, and 2) $\mathrm{D}_{2}$-type receptors expressed both pre- and postsynaptically, consisting of $\mathrm{D}_{2}$ (short), $\mathrm{D}_{2}$ (long), $\mathrm{D}_{3}$ and $\mathrm{D}_{4}$. Stimulation of $\mathrm{D}_{1}$-type receptors causes increased cAMP production (activating), whereas stimulation of $\mathrm{D}_{2}$-type receptors causes inhibition of cAMP production (inhibiting). The effects of these receptors give dopamine the classification of a modulatory neurotransmitter. For a simplified PFC dopamine synapse diagram, see Figure 2. 

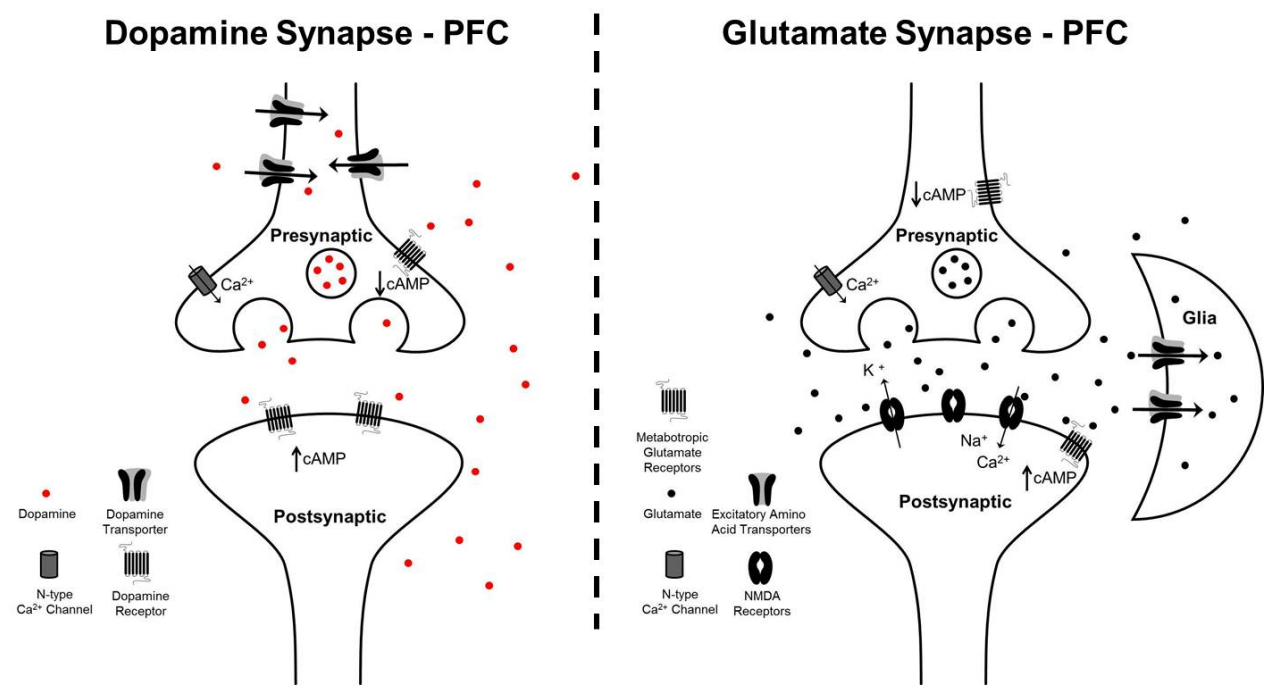

Figure 2. Dopaminergic and glutamatergic synapses in the PFC, simplified. Left: pre-synaptically, dopamine is transported into vesicles, which release their contents upon increase of the $\mathrm{Ca}^{2+}$ concentration. Synaptic dopamine is then able to stimulate dopamine receptors on both the pre- and postsynaptic neurons before it is cleared by the DAT or metabolism. Right: presynaptically, glutamate is stored in vesicles and then released into the extracellular space. Synaptic glutamate is then able to stimulate glutamate receptors (here represented as the NMDA and mGluR) on both the pre- and postsynaptic neurons before it is cleared by the EAAT located on nearby glial cells.

\subsection{Glutamate}

Recent clinical evidence has implicated glutamate in ADHD. Much of the initial evidence stems from proton magnetic resonance spectroscopy studies of children and adults with ADHD. These studies have shown increased levels of a marker for glutamate in the striatum and anterior cingulate cortex of the PFC [13-15]. Based on this evidence, new investigations into glutamatergic function in ADHD are ongoing. Glutamate is the major excitatory neurotransmitter in the central nervous system and must be tightly regulated for proper neuronal signaling to occur [16]. Unlike dopamine, glutamate is in abundance in most areas of the brain. Glutamate projections originating in the PFC extend to the striatum, NA, VTA and SN of the midbrain (see Figure 1). Glutamate is produced in the nerve terminals of these projections from two sources: 1) the Krebs cycle and 2) glutamine produced and excreted into the extracellular space via glial cells. Once produced, glutamate is transported into vesicles via the vesicular glutamate transporter (VGLUT) and when $\mathrm{Ca}^{2+}$ levels increase to cause an action potential, vesicles stored with glutamate bind to the cellular membrane and release their contents. Clearance of glutamate after this calcium-dependent release into the extracellular space is primarily performed by the membrane-bound glutamate transporter, called the excitatory amino acid transporter (EAAT), located on the presynaptic neuron and to the greatest extent by surrounding glial cells. The glutamate is primarily taken up by the EAATs located on the glial cells 
and is converted by glutamine synthetase into glutamine and transported out of the glial cell by system $\mathrm{N}$ transporter. The glutamine is then taken up by the system A transporter on the presynaptic neuron to help replenish glutamate levels through the mitochondrial bound glutaminase [11]. Glutamate acts on synaptic glutamate receptors in the target brain region, which are classified into two major types: 1) ionotropic, which include the NMDA, AMPA and kainate receptors and 2) metabotropic, including the excitatory mGluRs 1 and 5 (postsynaptic) and the inhibitory mGluRs 2, 3, 4, 6, 7, and 8 (presynaptic). For a simplified PFC glutamate synapse diagram, see Figure 2.

\subsection{Dopamine and glutamate interactions}

A dysfunctional interaction between the dopamine and glutamate systems has been implicated in numerous neuropsychiatric disorders such as drug addiction, Alzheimer's disease, schizophrenia, and ADHD. The brain regions most often linked to these disorders and the dopamine-glutamate dysfunction are the PFC and striatum, as these regions both receive heavy innervation from the dopaminergic SN/VTA and glutamate innervation from thalamic relays and other glutamate rich regions, as described in the previous section.

Studies of signaling interactions between the dopaminergic and glutamatergic systems demonstrate that the NMDA receptor is crucial in activating dopamine neurons in the VTA/SN $[17,18]$. Also, it has been found that stimulation of the $\mathrm{D}_{2}$-class dopamine receptor is involved in the downstream inhibition of the NMDA receptor, weakening the excitatory response to those neurons [19]. Likewise, it was found that activation of $\mathrm{D}_{4}$ receptors depressed AMPA receptor-mediated excitatory synaptic transmission in PFC pyramidal neurons, which was accompanied by a $\mathrm{D}_{4}$-induced decrease of AMPA receptors at the synapse [20]. These results provide substantial evidence that the dopamine and glutamate neuronal systems work in tandem to create a balance of neurotransmission in these regions.

The hypodopaminergic theory of ADHD asserts that the hyperactive and inattentive behaviors are caused by low levels of either tonic or phasic dopamine. If true, decreased dopamine released in the striatum and PFC would then be expected to lead to more active NMDA and AMPA receptors based on the studies mentioned above resulting in increased glutamatergic output to the striatum and SN/VTA, as well as an increased glutamate signal to the PFC. Glutamate coming into the SN/VTA would normally go on to release more dopamine [17]; however, in the ADHD brain, this feedback does not seem to occur.

\subsection{Translational neuropharmacology of ADHD treatments}

Investigations into the effects of stimulant action on the dopaminergic system have revealed that these medications increase extracellular dopamine levels via numerous mechanisms. First, amphetamine has been found to increase dopamine through calcium-independent mechanisms such as increased release of dopamine and blocking the reuptake of dopamine through the DAT [21, 22]. Methylphenidate (MPH), another stimulant medication commonly used to treat ADHD, increases dopamine levels by inhibiting dopamine reuptake via the DAT [23-29]. 
The non-stimulant medication atomoxetine (ATX) is becoming increasingly popular as a treatment for ADHD compared to the stimulant medications because it has lower abuse liability. ATX has been found to increase levels of the catecholamines by selectively blocking the norepinephrine transporter (NET), which is also able to clear dopamine [30-32] and, like stimulants, is effective at lessoning the intensity of ADHD symptoms [33-36]. In vitro work has shown that ATX acts as an NMDA receptor antagonist [37], providing preliminary evidence that current treatments for ADHD may have a direct effect on the glutamatergic system.

Using magnetic resonance spectroscopy, it was found that children treated with ATX, but not $\mathrm{MPH}$, had decreased levels of a marker for glutamate/glutamine in the PFC, though $\mathrm{MPH}$ was able to decrease glutamate in the anterior cingulate cortex [38]. In the striatum, both ATX and MPH decreased the glutamate/glutamine marker levels compared to controls [13]. These results suggest that ATX may be regulating and activating prefrontal cortex neurons. However, another clinical study using a similar technique found that chronic long-acting MPH decreased glutamate levels in the PFC of children with ADHD [39]. Wiguna et al. (2012) also discovered that MPH treatment resulted in an increase in the amount of and functional state of the neurons in the PFC, supporting that the current ADHD stimulant treatment MPH can activate PFC neurons as well. Further evidence of PFC activation comes from a study of brain-derived neurotropic factor (BDNF), a marker for neuronal plasticity. ATX was found to increase BDNF expression in the PFC; however, MPH had the opposite effect and reduced BDNF expression in the PFC [40], though it must be noted that this study was completed in naïve rodents and may explain why these results do not match those seen in ADHD patients.

Many second-line and experimental treatments for ADHD are now targeting both the dopamine and glutamate systems. Memantine is an uncompetitive NMDA receptor antagonist [41] and has also been found to act as a $\mathrm{D}_{2}$ receptor agonist [42]. It has been approved and used as a treatment for Alzheimer's disease; however, in an 8 week openlabel pilot study in children with ADHD, memantine was found to improve ADHD symptoms (Findling et al, 2007). Surman et al. (2011) extended these findings to adults with ADHD in a separate open-label study lasting 12 weeks and found similar results, with memantine improving ADHD symptoms and neuropsychological performance [43]. The MAO-B inhibitor (deprenyl), which stops the degradation of dopamine and is used as a treatment in Parkinson's disease, was found to alleviate ADHD symptoms [44, 45]. These clinical data using glutamate and dopamine altering drugs provide strong links for dysfunctional dopamine-glutamate interactions in ADHD, though the importance of this dysfunction is still unknown. Based on these data, we believe it's important to not overlook the possible role of dysfunctional dopamine-glutamate interactions, but to instead focus on this relationship. Animal models of ADHD provide a unique opportunity to investigate neurotransmitter system dysfunction as well as to develop novel ways to treat ADHD targeting these systems. We will next highlight two separate models of ADHD and how they are implicating both dopamine and glutamate dysfunction in ADHD. 


\subsection{Animal models of ADHD: Hypotheses}

\section{The spontaneously hypertensive rat}

The spontaneously hypertensive rat (SHR) has been used as an animal model for ADHD combined type since the 1970's because of its sustained attention deficits [46], motor impulsiveness [47-49], and hyperactivity [46] with the hyperactivity absent in novel situations [50]. Currently, there exists conflicting data on dopamine release and uptake levels in the brain areas thought to be involved in the pathophysiology of ADHD, including the PFC [51]. Our lab has previously reported enhanced dopamine uptake in the ventral striatum and nucleus accumbens core of the SHR [52]; however, investigations into PFC dopamine regulation are still not clear. The PFC of the SHR has been reported to have decreased dopamine uptake [53], yet a study found no differences in the levels of DAT, tyrosine hydroxylase, $D_{1}, D_{2}, D_{3}, D_{5}$ receptors, and dopamine- $\beta$-hydroxylase between the SHR and its progenitor strain, the Wistar Kyoto (WKY), in the PFC. Regional differences in the $\mathrm{D}_{4}$ receptors in the PFC were found, providing evidence that the SHR's $\mathrm{D}_{4}$ levels are lower than those of the WKY [54]. Further, it was found that PFC AMPA receptor activity was increased in the SHR [55] and inhibitory dopaminergic activity was found to be decreased while noradrenergic activity increased in the SHR [56]. These findings all convey a message that dopamine regulation is dysfunctional in the PFC of the SHR model of ADHD; however, direct observation of in vivo dopamine dynamics in the separate PFC sub-regions (cingulate, prelimbic, and infralimbic) of the SHR have not yet been accurately defined.

\section{The dopamine receptor D4 knockout mouse}

The correlation between ADHD and the 7-repeat polymorphism in the dopamine D4 receptor (DRD4.7) is supported by neuroanatomical, neurochemical, molecular genetics and pharmacological studies [57-60]. Recently, the DRD4.7 was identified as having the most significant genetic relationship to ADHD in pooled family and case-controlled studies [61]. Clinical studies in adolescents report that ADHD patients with the DRD4.7 have thinner frontal cortical structures in comparison to age matched controls [62]. The highest concentration of DRD4s is in the frontal cortex, an area implicated in the pathophysiology of ADHD using neuroimaging and neuropsychological evaluation of ADHD patients [63-66]. There is evidence that changes in DRD4 expression can affect glutamate levels in the striatum of DRD4 ${ }^{-/}$mice [67]. Previous studies show that DRD4 ${ }^{-/}$mice are supersensitive to ethanol, cocaine and methamphetamine [68]; have enhanced reactivity to unconditioned fear [69]; reduced exploration of novel stimuli [70]; and hypersensitivity to amphetamine [71]. In the cortex, hyperexcitability has been demonstrated in DRD4 ${ }^{-/}$mice using immunohistochemical, electrophysiological, pharmacological and ultrastructural methods, indicating that DRD4 activation has an inhibitory influence on glutamate neurons in the frontal cortex [72]. At this time, no direct studies of in vivo glutamate have been investigated in the intact PFC of the DRD4 ${ }^{--}$mouse. Therefore, in vivo measures of glutamatergic modulation in the PFC may correlate changes in glutamate neurotransmission to the expression levels of the DRD4 and understanding the physiological role of the DRD4 may elucidate the importance of dopamine and glutamate interactions in the PFC. 


\section{Measuring neurotransmitters in these rodent models of ADHD}

Recent studies point to the importance of a dysfunctional relationship between dopaminergic and glutamatergic neurotransmission in ADHD, therefore new investigations into this relationship are necessary to improve our understanding and may lead to improved therapeutics for ADHD. Based on our development of novel and revolutionary methods of measuring dopamine and glutamate in vivo, we realize we are in a unique position to test our hypotheses that dopamine and glutamate regulation play a major role in the pathophysiology of ADHD. The development of carbon fiber microelectrodes and glutamate oxidase-coated microelectrode arrays (MEAs) provide improved spatial resolution, sub-second temporal resolution, and low limits of detection $(<10 \mathrm{nM}$ for dopamine [52], $<0.2 \mu \mathrm{M}$ for glutamate [73]) over conventional techniques used in the past, such as microdialysis. The smaller size of these probes and decreased damage to tissue compared to microdialysis probes allows for the in vivo characterization of dopamine and glutamate signaling closer to the synapse. Using these technologies, we were able to explore if dysfunction in dopamine and glutamate neurotransmission occur in the PFC of the SHR and DRD4 models of ADHD. The studies described here could potentially lead to the development of novel therapies for ADHD, which will be discussed in detail later.

\subsection{Neurotransmitter recording techniques: Methods}

\section{High-speed chronoamperometric recordings of dopamine release and uptake in the PFC} of the SHR

Male, 8-10 weeks old, inbred spontaneously hypertensive rats (SHR, average $225 \mathrm{~g}$, average PND 60), inbred Wistar Kyoto rats (WKY, average $210 \mathrm{~g}$, average PND 61), and outbred Sprague Dawley rats (SD, average $289 \mathrm{~g}$, average PND 69) were obtained from Charles River Laboratories (NCrl), Wilmington, Massachusetts. Animals were given access to food and water ad libitum and housed in a 12 hour light/dark cycle. Protocols for animal use were approved by the Institutional Animal Care and Use Committee, which is Association for Assessment and Accreditation of Laboratory Animal Care International approved. All procedures were carried out in accordance with the National Institutes of Health Guide for Care and Use of Laboratory Animals and all efforts were made to minimize animal suffering and to reduce the number of animals used.

High-speed chronoamperometric measurements (1 Hz sampling rate, $200 \mathrm{~ms}$ total) were performed using the FAST16mkII recording system (Fast Analytical Sensing Technology, Quanteon, LLC, Nicholasville, Kentucky) as previously described [52, 74]. Single carbon fiber electrodes (SF1A; $30 \mu \mathrm{m}$ outer diameter $\times 150 \mu$ m length; Quanteon, LLC, Nicholasville, Kentucky) were coated with Nafion ${ }^{\circledast}\left(5 \%\right.$ solution, $1-3$ coats at $180^{\circ} \mathrm{C}$, Aldrich Chemical Co., Milwaukee, Wisconsin) prior to an in vitro calibration used to determine selectivity, limit of detection, and sensitivity before use in vivo: average selectivity for all microelectrodes used in these experiments was $1877 \pm 664 \mu \mathrm{M}$ for dopamine vs. ascorbic acid; average limit of detection for the measurement of dopamine was $0.028 \pm 0.008 \mu \mathrm{M}(\mathrm{S} / \mathrm{N}$ of 3); average slope for the electrodes was $-0.492 \pm 0.111 \mathrm{nA} / \mu \mathrm{M}$ dopamine. After calibration, miniature $\mathrm{Ag} / \mathrm{AgCl}$ reference electrodes were prepared as previously described [74]. The carbon fiber microelec- 
trode was affixed to a micropipette $(10 \mu \mathrm{m}$ inner diameter $)$ which was positioned approximately $200 \mu \mathrm{m}$ from the carbon fiber electrode tip using sticky wax (Kerr USA, Romulus, Michigan).

Rats were anesthetized intraperitonealy (i.p.) using a 25\% urethane solution $(1.25 \mathrm{~g} / \mathrm{kg}$ ) and placed in a stereotaxic frame (David Kopf Instruments, Tujunga, California). A circulating heating pad (Gaymar Industries, Inc., Orchard Park, New York) was used to maintain body temperature. The skull was removed bilaterally for recordings in the PFC (AP +3.2, ML \pm 1.0 , DV -2 to -6 in $0.5 \mathrm{~mm}$ increments) [75]. A small hole remote from the site of surgery was drilled for placement of the miniature $\mathrm{Ag} / \mathrm{AgCl}$ reference electrode. Prior to experimentation, the micropipette was filled with filtered isotonic $\mathrm{KCl}(120 \mathrm{mM} \mathrm{KCl}, 29 \mathrm{mM} \mathrm{NaCl}, 2.5$ $\mathrm{mM} \mathrm{CaCl}_{2} \bullet 2 \mathrm{H}_{2} \mathrm{O}$ ) solution ( $\mathrm{pH}$ 7.2-7.4) using a 4 inch filling needle (Cadence Inc., Staunton, Virginia) and a $5 \mathrm{ml}$ syringe. Experiments were then initiated with the insertion of the micropipette/microelectrode assembly into a stereotactically selected region of the left or right hemisphere's PFC. After a 30-45 minute baseline, the effect of a single local application of $\mathrm{KCl}$ on dopamine release was determined [52]. The $\mathrm{KCl}$ solution was locally applied by pressure ejection (5-25 psi for 0.5 seconds) and the single application of a set volume of $\mathrm{KCl}$ (75-125 nl) was delivered to each sub-region, measured by determining the amount of fluid ejected from the micropipette using a dissection microscope fitted with an eyepiece reticule that was calibrated so that $1 \mathrm{~mm}$ of movement was equivalent to $25 \mathrm{nl}$ of fluid ejected [76, 77]. If the volume was determined to be greater or less than $75-100 \mathrm{nl}$, then that data point was excluded. After the $\mathrm{KCl}$ studies, the micropipette/microelectrode assembly was filled with filtered isotonic $200 \mu \mathrm{M}$ dopamine solution containing $100 \mu \mathrm{M}$ ascorbic acid (an antioxidant) in $0.9 \%$ saline ( $\mathrm{pH} 7.2-7.4$ ). The micropipette/microelectrode assembly was inserted stereotactically into the animal's contralateral PFC. Again, a stable baseline was achieved before the dopamine solution was locally applied by pressure ejection (10-30 psi for $0.5-10 \mathrm{~s})$ to achieve a maximum amplitude between the range of 0.5 to $1 \mu \mathrm{M}$ dopamine. The maximum concentration of the dopamine in the extracellular space was measured by subtracting the apex of the recorded peak from the baseline recorded prior to the ejection. If the peak amplitude was greater or less than 0.5 to $1 \mu \mathrm{M}$ dopamine, then that data point was excluded. Brains were removed and processed (frozen) for histological evaluation of microelectrode recording tracks. Only data from histologically confirmed placements of microelectrodes into the PFC were used for final data analysis. Based on histological analyses, no animals were excluded due to microelectrode placement errors.

Collected data were processed using a custom Matlab®-based analysis package. For $\mathrm{KCl}$ evoked DA release, maximum amplitude of the evoked dopamine peak was used. The volume of $\mathrm{KCl}$ applied was kept constant across depths and strains (75-125 nl). For dopamine uptake the time to $80 \%$ decay of the dopamine signal (T80) was examined. dopamine signals were amplitude matched (ranging from 0.5 to $1 \mu \mathrm{M}$ dopamine) to ensure accurate measurement of dopamine uptake kinetics $[52,74]$. Outliers were excluded via the Grubb's test before averaging if the conditions for homogeneity of variance were met. To compare dopamine dynamics in the separate PFC subregions, one-way ANOVAs followed by Bonferroni post-hoc comparisons were used. Significance was set at $\mathrm{p}<0.05$ (GraphPad Prism 5.0). 
Urethane, dopamine, ascorbic acid, sodium chloride, potassium chloride, calcium chloride and Nafion ${ }^{\circledR}$ were obtained from Sigma (St. Louis, MO). Carbon fiber microelectrodes (SF1A's) were fabricated by the Center for Microelectrode Technology.

\section{High-speed amperometric recordings of glutamate levels in the PFC of the DRD4 knock- out mouse}

Male mice (5-7 months; $32 \mathrm{~g}$ ) descended from the original F2 hybrid of mice with a truncated and non-expressing DRD4 gene (DRD44/-; 129/SvEv $\times$ C57BL/6J) were derived by backcrossing the DRD4 $4^{+-}$mouse line for 20 generations [68]. In all experiments, the DRD4 ${ }^{-/-}$mice $(\mathrm{n}=5-8)$ and DRD4 ${ }^{+/}(\mathrm{n}=5-9)$ were compared to litter-matched DRD4 ${ }^{+/+}(\mathrm{n}=5-8)$ animals. Mice were group-housed (2-4 per cage) with unlimited access to food and water. Mice were maintained on a twelve hour light/dark cycle. Protocols for animal use were approved by the Institutional Animal Care and Use Committee (IACUC), which is Association for Assessment and Accreditation of Laboratory Animal Care International approved, and all procedures were carried out in accordance with the National Institutes of Health Guide for Care and Use of Laboratory Animals.

Ceramic-based microelectrode arrays (MEA) that contained 4 platinum (Pt) recording surfaces (sites 1-4) in an S2 configuration (two sets of side-by-side recording sites) were prepared to selectively measure glutamate. The electrodes were fabricated for in vivo recordings using published methods [73, 78, 79]. All 4 sites were electroplated with meta-phenylene diamine (mPD) by applying a potential of $+0.5 \mathrm{~V}$ to the Pt sites vs. a silver/silver chloride (Ag/ $\mathrm{AgCl}$ ) reference electrode (Bioanalytical Systems, RE-5) in a deoxygenated $0.05 \mathrm{M}$ phosphate buffered saline (PBS; pH 7.1-7.4) with $5 \mathrm{mM}$ mPD. The mPD forms a size-exclusion layer over the sites, blocking dopamine, ascorbic acid (AA), DOPAC, and other electroactive compounds. Pt sites 1 and 2 were coated with glutamate oxidase (Glu-Ox) within an inert protein matrix of bovine serum albumin (BSA) and gluteraldehyde, enabling these sites to detect glutamate levels on a sub-second timescale with low levels of detection $(0.2 \mu \mathrm{M})$. Sites 3 and 4 were coated with only BSA and gluteraldehyde [80, 81]. In the presence of Glu-Ox, glutamate is broken down into $\alpha$-ketoglutarate and peroxide $\left(\mathrm{H}_{2} \mathrm{O}_{2}\right)$. The $\mathrm{H}_{2} \mathrm{O}_{2}$ is small enough to traverse the mPD layer and is readily oxidized and recorded as current using the FAST-16 equipment (Fast Analytical Sensor Technology (FAST); Quanteon L.L.C., Nicholasville, KY). For calibration details, see $[73,78]$. From the calibration, average values for slope were $-7.7 \pm 4.8 \mathrm{pA} / \mu \mathrm{M}$, selectivity $214 \pm 64$ to 1 and LOD $0.59 \pm 0.06 \mu \mathrm{M}$ ( $\mathrm{n}=26$ electrodes; 51 glutamate recording sites). After the MEA was calibrated; a single barrel glass capillary with filament (1.0 x $0.58 \mathrm{~mm}^{2}, 6$ ", A-M Systems, Inc., Everett, WA) was pulled using a Kopf Pipette Puller (David Kopf Instruments, Tujunga, CA) and bumped against a glass rod so that the inner diameter of the micropipette was 10-12 $\mu \mathrm{m}$. The tip of the micropipette was placed between the $4 \mathrm{Pt}$ recording sites, approximately 50-80 $\mu \mathrm{m}$ away from the electrode surface and secured using Sticky Wax (Kerr Manufacturing Co, Detroit, Michigan).

Mice were anesthetized using i.p. injections of $10 \%$ urethane solution $(1.25 \mathrm{~g} / \mathrm{kg})$ and placed in a stereotaxic frame (David Kopf Instruments, Tujunga, CA) fitted with a Cunningham ${ }^{\mathrm{TM}}$ Mouse and Neonatal Rat Adaptor (Stoelting Co., Wood Dale, IL). A circulating heating pad (Gaymar Industries, Inc., Orchard Park, NY) was used to maintain body temperature. The 
skull overlying the PFC was removed bilaterally. The MEA-micropipette assembly was positioned in the brain according to the following stereotaxic coordinates where all anteriorposterior $(\mathrm{AP})$ measures were from bregma, medial-lateral $(\mathrm{ML})$ measures were from midline and dorsal-ventral (DV) measures were from dura: AP: $+2 \mathrm{~mm}, \mathrm{ML}: \pm 1 \mathrm{~mm}, \mathrm{DV}:-1.8$ to $2.6 \mathrm{~mm}$ at an angle of 8 degrees according to the atlas of The Mouse Brain in Stereotaxic Coordinates [82]. An additional hole, remote from the surgery site, was opened for a $\mathrm{Ag} / \mathrm{AgCl}$ reference electrode. Prior to placement of the MEA-pipette assembly, the micropipette was filled with isotonic $125 \mu \mathrm{M}$ glutamate $(125 \mu \mathrm{M}$ L-glutamate in $0.9 \%$ physiological saline; $\mathrm{pH}=7.2-7.4$ ) using a combination of a $1 \mathrm{ml}$ syringe filled with glutamate solution, a $0.22 \mu \mathrm{m}$ sterile syringe filter (Costar Corporation), and a 4" stainless steel pulled needle (30 gauge, beveled tip; Popper and Son, Inc., NY). A potential of $+0.7 \mathrm{~V}$ was applied versus a miniature $\mathrm{Ag} / \mathrm{AgCl}$ reference electrode and the data were displayed at a frequency of $2 \mathrm{~Hz}$. Upon stereotaxic placement of the MEA-micropipette assembly, 10-20 minutes of baseline data were acquired. Extracellular levels of glutamate were measured by averaging 30 seconds of baseline recordings prior to application of glutamate or $\mathrm{KCl}$. Then, a $125 \mu \mathrm{M}$ glutamate solution was locally applied via pressure ejection using a Picospritzer II connected to the open end of the micropipette by plastic tubing (Parker Hannifin Corp., General Valve Corporation). Pressure was applied at 5-25 psi for 1 second in all of the experiments. Glutamate was applied every 30-60 seconds for a total of 10 recordings. The MEA was then lowered in $350 \mu \mathrm{m}$ increments. Baseline recordings were acquired for 5-10 minutes and the recordings were repeated. Parameters from three of the ten signals ranging from 10-30 $\mu \mathrm{M}$ in amplitude were averaged for each Pt electrode site at each depth. Signals were analyzed for time required to rise to maximum amplitude (rise time), time for $80 \%$ of the signal to decay from maximum amplitude (T80), and the rate of uptake. The uptake rate was calculated by multiplying the first order rate constant $\left(\mathrm{k}^{-1}\right.$, seconds $\left.\mathrm{s}^{-1}\right)$ by the maximum amplitude (uptake rate $=\mu \mathrm{M} / \mathrm{s}$ ) [81]. All data from local applications of glutamate from a given site were pooled into a single point. Amplitude-matched signals were compared to assess genotypic differences in the rates of clearance of exogenous glutamate [83]. Brains were removed and processed for histological evaluation of microelectrode recording tracts. Only data from histologically confirmed placements of microelectrodes within the PFC were used for final data analysis.

Data from the side-by-side recordings were averaged and used as a single data point. If only one microelectrode site provided usable data, then the recordings were reported as from that site. Very few data points were omitted in this study due to outlier status, with exception for constraints on amplitude-matching. To determine statistical significance $(p<0.05)$, processed data were analyzed using a one-way ANOVA with Tukey's post-hoc comparisons across all genotypes (Graphpad Prism 4.0). Urethane, L-glutamate, dopamine, ascorbic acid, and 1,3-phenylenediamine dihydrochloride were obtained from Sigma-Alderich, St. Louis MO). Microelectrode arrays were provided by Quanteon L.L.C. (Nicholasville, KY).

\subsection{Dopamine dysfunction in the PFC of the SHR model of ADHD: Results}

High-speed chronoamperometry coupled with carbon fiber microelectrodes was used to evaluate $\mathrm{KCl}$-evoked dopamine release because of its capability to record dopamine release 
within sub-regions of the striatum and the NA $[52,74]$ using a local application of 75-125 nl $\mathrm{KCl}$ in $500 \mu \mathrm{m}$ increments. To examine potential differences in evoked dopamine release in the separate sub-regions of the PFC between the outbred SD, the WKY progenitor, and the SHR model of ADHD, one-way ANOVAs were used. No significant differences were found between strains (cingulate cortex, $\mathrm{p}=0.1295$; prelimbic cortex, $\mathrm{p}=0.1998$; infralimbic cortex, $\mathrm{p}=0.1050$ ). These data suggests that the cingulate, prelimbic and infralimbic regions in all three strains have a similar capacity to release dopamine during an action potential event. It's important to note that in both the SD and SHR strains, dopamine peak amplitudes increased as the microelectrode was moved ventrally; however, the WKY strain displayed the opposite effect. See Figure 3. Note that all dopamine signals were indicative of the detection of dopamine and/or norepinephrine based on the reduction/oxidation rations of the signals that averaged $\sim 0.8-1.0$ for all recordings.
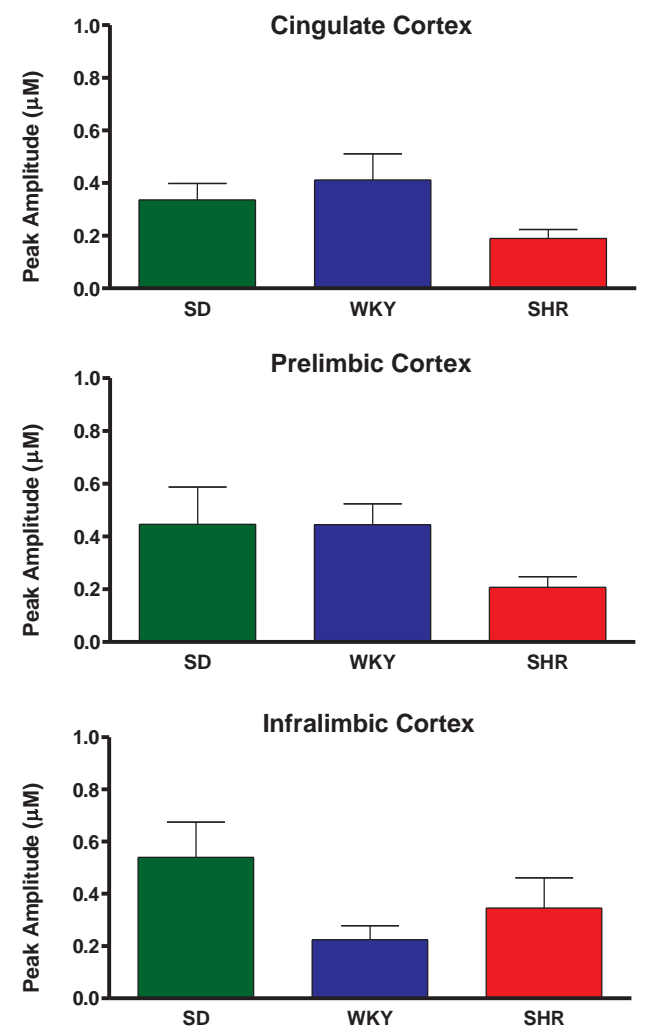

Figure 3. No differences were observed between the outbred SD control strain, the WKY progenitor strain, and the SHR model of ADHD in the $\mathrm{KCl}$-evoked dopamine peak amplitudes following a local application of $\mathrm{KCl}$ in any of the prefrontal cortical sub-regions. Values represent the mean \pm SEM. 

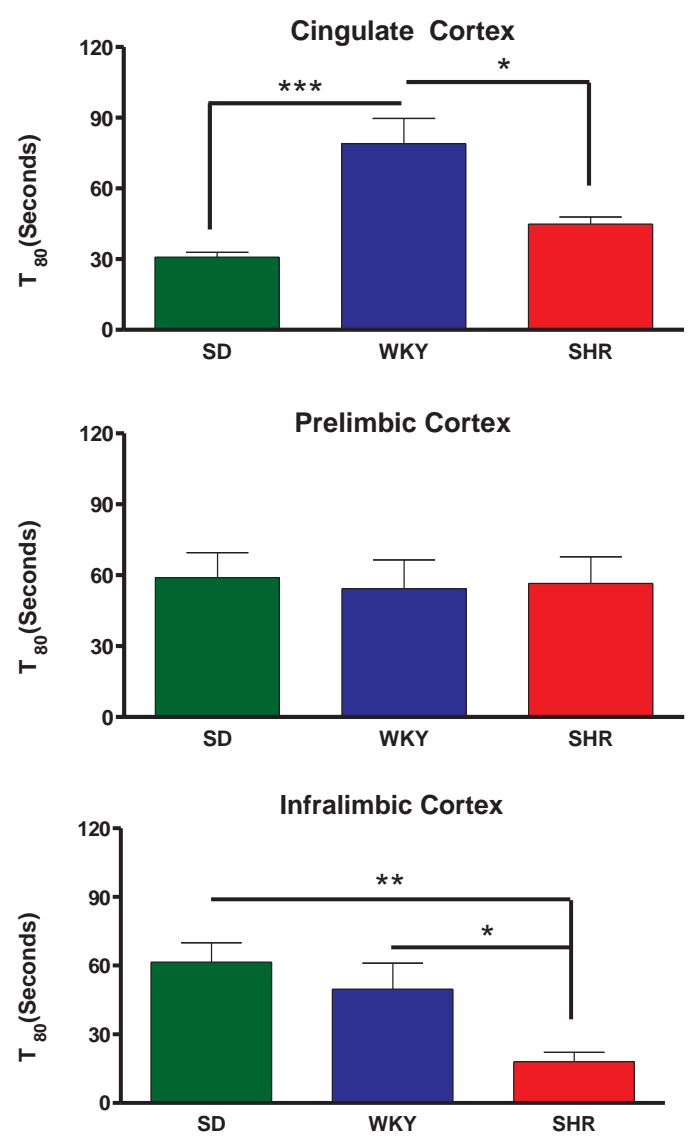

Figure 4. The SHR model of ADHD and the outbred SD control strain exhibited significantly faster dopamine uptake than the WKY strain in the cingulate cortex $\left({ }^{*} p<0.05,{ }^{* * *} p<0.001\right)$. No dopamine uptake differences were observed in the prelimbic cortex; however, the SHR exhibited significantly faster dopamine uptake in the infralimbic cortex compared to both the SD control and WKY strain $\left({ }^{*} p<0.05,{ }^{* *} p<0.01\right)$. Values represent the mean \pm SEM.

To examine differences in dopamine uptake in the separate prefrontal cortical sub-regions, we used local applications of dopamine to directly observe the functional properties of the dopamine and norepinephrine transporters. One-way ANOVAs followed by Bonferroni post-hoc comparisons were used in each sub-region. It was discovered that the SHR model of ADHD $(p<0.05)$ and the outbred SD control strain $(p<0.001)$ displayed significantly faster dopamine uptake compared to the WKY strain in the cingulate cortex $\left(\mathrm{F}_{(2,23)}=11.11\right)$. The average dopamine uptake times in the cingulate cortex were: SD, $30.8 \pm 2$ seconds; WKY, $79.1 \pm 10$ seconds; and SHR, $44.8 \pm 3$ seconds. No dopamine uptake differences were observed in the prelimbic cortex $(\mathrm{p}=0.9605)$; however, the SHR exhibited significantly faster 
dopamine uptake compared to both the SD control $(p<0.01)$ and the WKY strain $(p<0.05)$ in the infralimbic cortex $\left(\mathrm{F}_{(2,28)}=6.53\right)$. The average dopamine uptake times in the infralimbic cortex were: SD, $61.6 \pm 8$ seconds; WKY, $49.8 \pm 11$ seconds; and SHR, $18 \pm 4$ seconds. These data reveal that the dopamine and norepinephrine transporters clear dopamine faster in the SHR in the cingulate and infralimbic cortices compared to control, but not the prelimbic cortex. It's important to note that as the microelectrode was moved ventrally in the control SD strain, the dopamine uptake became slower; however, in the WKY and SHR strains, dopamine uptake became faster as the electrode moved ventrally.

\subsection{Glutamate dysfunction in the PFC of the DRD4-/- mouse model of ADHD: Results}

In order to evaluate the effect of DRD4s on extracellular levels of glutamate, we compared extracellular glutamate levels across genotypes in the PFC. Extracellular resting levels of glutamate were higher by approximately $73 \%$ in the PFC of DRD4 ${ }^{-/}$mice in comparison to their DRD4 $4^{+++}$littermates $\left(\mathrm{DRD}^{+++}: 1.4 \pm 0.2 \mu \mathrm{M}, \mathrm{n}=8\right.$, signals=22; DRD4 $4^{+/}$: $1.9 \pm 0.3 \mu \mathrm{M}, \mathrm{n}=8$, signals=23; DRD4 ${ }^{-/}: 2.5 \pm 0.3 \mu \mathrm{M}, \mathrm{n}=8$, signals=24; $p<0.05$, see Figure 5). A depth analysis showed that $\mathrm{DRD}^{+/+}$mice maintained similar extracellular resting glutamate levels across depths $(1.4 \pm 0.3 \mu \mathrm{M})$, while DRD4 ${ }^{-/}$mice tended to have higher levels throughout all areas. The most profound difference was the stepwise increase in extracellular glutamate levels in the cingulate cortex with a significant difference observed between the DRD4 ${ }^{+/+}$and DRD4 ${ }^{--}$mice $\left(\mathrm{DRD}^{+/+}: 1.4 \pm 0.3 \mu \mathrm{M}, \mathrm{n}=8\right.$; DRD4 $4^{+--}: 2.0 \pm$ $0.6 \mu \mathrm{M}, \mathrm{n}=7$; DRD4 ${ }^{-/}: 3.0 \pm 0.7 \mu \mathrm{M}, \mathrm{n}=8$; Student's t-test: $p<0.05$; see Figure 5) These data indicate that the loss of DRD4s results in increased extracellular resting glutamate levels in the PFC, most dramatically in the cingulate cortex.

The in vivo activity of glutamate uptake was examined with a high degree of temporal and spatial resolution by locally applying exogenous glutamate to the extracellular space of the brain and measuring the presence and successive clearance kinetics. Resulting data provided kinetic measures that allowed us to evaluate the efficiency of exogenous glutamate removal from the extracellular space within the 3 different brain areas of the medial PFC. Statistical comparisons were made on amplitude-matched data in order to make sure that variations in maximum amplitude would not contribute to changes in rise time, uptake rate and T80. Average maximum amplitudes were $15.39 \pm 1.30 \mu \mathrm{M}(\mathrm{n}=8$; signals= 21), $13.62 \pm 0.78$ $\mu \mathrm{M}(\mathrm{n}=9$; signals $=25)$ and $13.93 \pm 0.91 \mu \mathrm{M}(\mathrm{n}=8$; signals $=21)$ in the DRD4 ${ }^{+/+}, \mathrm{DRD}^{+/-}$and $\mathrm{DRD}^{-/}$, respectively. Uptake rates within the PFC were similar across genotypes (DRD4 $4^{+++}$: $4.85 \pm 0.69 \mu \mathrm{M}, \mathrm{n}=8$; DRD4 $4^{+-}: 4.82 \pm 0.46 \mu \mathrm{M}, \mathrm{n}=9$; DRD4 ${ }^{-/}: 5.28 \pm 0.74 \mu \mathrm{M}, \mathrm{n}=8$; see Figure 6). The time it took for $80 \%$ of the signal to decay (T80) was significantly longer in DRD4 $4^{-/}$mice than wildtype (DRD4 $4^{+/}: 2.50 \pm 0.16 \mu \mathrm{M}, \mathrm{n}=8$; $\mathrm{DRD}^{+/-}: 2.84 \pm 0.12 \mu \mathrm{M}, \mathrm{n}=9$; DRD4 $4^{-/}: 3.00 \pm 0.14$ $\mu \mathrm{M}, \mathrm{n}=8 ; p<0.05)$ with the most profound changes occurring in the prelimbic area $(p<0.05)$. These kinetic measures of glutamate clearance in the PFC indicate that the DRD4 may play an important role in glutamate clearance. 


\section{PFC Tonic Glutamate}
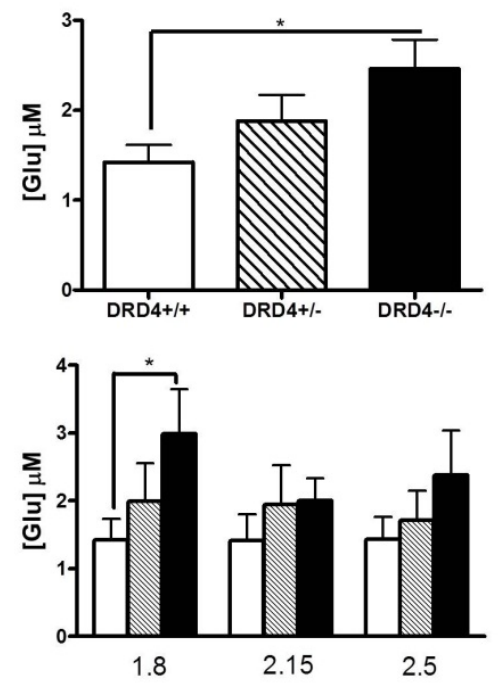

Figure 5. Extracellular resting levels of glutamate in the PFC. The top bar graph shows increased extracellular levels of glutamate in the PFC of DRD4 ${ }^{-/}$in comparison to DRD4 ${ }^{+/+}$mice $\left({ }^{*} p<0.05\right)$. The bottom graph depicts extracellular resting glutamate levels broken down by depth in the PFC. The numbers on the x-axis represent the depth of the microelectrode $(1.8,2.15$ and $2.5 \mathrm{~mm})$ and indicate the cingulate cortex, the prelimbic area and the infralimbic area; respectively. Values represent the mean \pm SEM.

\subsection{Implications of dysfunctional neurotransmitter systems}

\section{The SHR and dopaminergic PFC dysfunction}

Based on current stimulant treatments for ADHD that target the dopaminergic system, such as $\mathrm{MPH}$, the hypofunctional catecholamine theory has evolved and states that behaviors seen with ADHD are caused by decreased levels of catecholamines in the brain regions associated with attention and reward processing [84] including the striatum and PFC. In the spontaneously hypertensive rat (SHR) model of ADHD, there have been conflicting reports of dopamine levels in the striatum and PFC; however, the techniques used varied with each study. Some studies revealed a hypodopaminergic tone $[85,86]$, while others found no difference in dopamine levels $[87,88]$. Microdialysis measures of dopamine levels in the SHR are at most unreliable and poorly reflect concentrations of dopamine near the synapse due to the limited spatial resolution $(>1 \mathrm{~mm})$, slow sampling rates $(1-20 \mathrm{~min})$, and significant damage to the surrounding tissue [89-91]. Based on this premise, it is necessary that a tech- 
nique with increased spatial and temporal resolution over microdialysis, such as carbon fiber microelectrodes coupled to high-speed chronoamperometric recordings, be used to measure dopamine dynamics in this popular animal model [92].
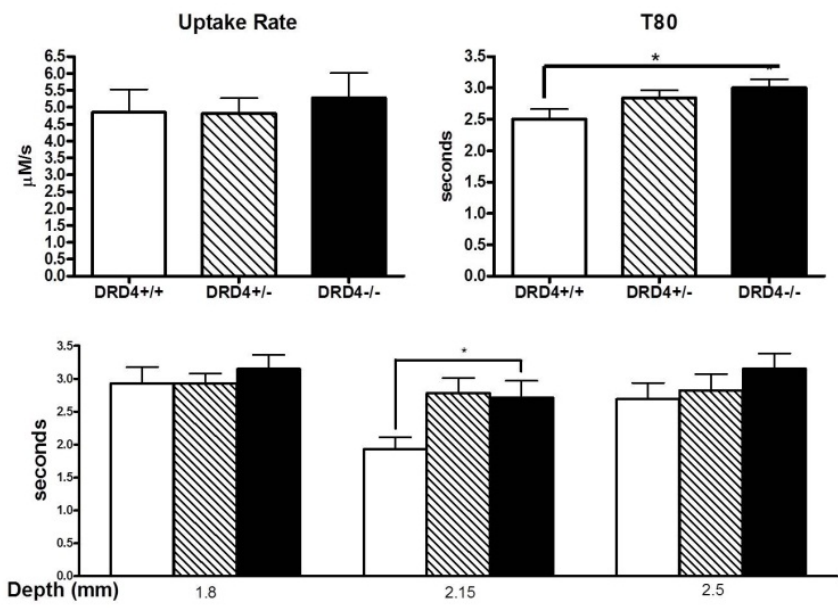

Figure 6. Glutamate clearance in the PFC. The top bar graphs represent changes in glutamate clearance in the PFC as a function of DRD4 expression for amplitude-matched signals. The T80 is significantly longer in DRD4 ${ }^{-1-}$ mice in comparison to $\mathrm{DRD}^{+/+}\left({ }^{*} p<0.05\right)$. A depth profile of the T80 values (bottom) indicate that the most significant difference was in the prelimbic area of the PFC $(2.15 \mathrm{~mm})$ in the DRD $4^{-}$. Values represent the mean $\pm \mathrm{SEM}$.

Recent data from our lab using carbon fiber microelectrodes with high-speed chronoamperometry have shown decreased potassium-evoked dopamine signals in the dorsal striatum of the SHR model of ADHD compared to the WKY, as well as faster dopamine uptake in the ventral striatum and NA core in the SHR compared to both the SD and WKY controls [52]. Previous investigations have implicated the dopamine transporter (DAT) in the dopamine dysfunction of the SHR model of ADHD [93-98] and our data revealing differences in dopamine regulation in the striatum can be attributed to increased activity of the DAT in the striatum of the SHR. It is reasonable to assume that if the striatum has increased DAT activi- 
ty, it's likely that similar dopamine dysfunction exists in the PFC of the SHR. It's important to clarify that the norepinephrine transporter (NET) is present in certain regions of the PFC in much greater concentrations than the DAT and dopamine uptake in the PFC is thought to be preferentially due to the NET instead of the DAT [99], so investigations into the mechanism of dopamine clearance in the PFC of the SHR should be examined in the future.

Using similar volumes of a potassium solution, evoked overflow of catecholamine nerve terminals surrounding the tip of the carbon fiber microeletrode was used to attempt to locate differences in vesicular dopamine storage in the different PFC sub-regions. Upon stimulation, no differences were observed between the inbred SHR model of ADHD, the inbred progenitor WKY and the outbred SD control strains. The lack of differences signifies to us that the separate PFC sub-regions all have the same capacity to store and release dopamine and/or norepinephrine in these strains. MAO and VMAT, both implicated in ADHD, can then be considered to be functional in the PFC of the SHR model of ADHD and drugs targeting these proteins, such as deprenyl, may not be useful in this model.

Though no differences were observed in the $\mathrm{KCl}$-evoked dopamine signals, there were significant differences in the length of time required to clear exogenous dopamine applications between the SHR and control strains. Similar maximum dopamine amplitudes were achieved by applying various volumes of an exogenous dopamine solution in order to evaluate the uptake kinetics of the signals. The DAT is electrogenic and depolarization causes the DAT to change from the basal state [100-104] and in order to test the full uptake capabilities of the transporters, including both the DAT and NET, it was necessary to study the transporters in their more natural state using local applications of dopamine. Utilizing this approach, it was discovered that the SHR displayed faster uptake in the cingulate and infralimbic cortices compared to the WKY strain, but not the prelimbic cortex. The SHR model of ADHD was also discovered to have faster dopamine uptake compared to the SD strain in the infralimbic cortex. These results are significant because the cingulate cortex is involved with learning and memory, playing a vital role in the Papez circuit and the cortical control of emotions in humans [105]. These data further demonstrate that there exists a neurochemical dysfunction in a region important for linking behavioral outcomes to motivation $[106,107]$ in the SHR. Also, the infralimbic cortex in rodents is known to be involved with attention to stimulus features, task contingencies, and attentional set-shifting [108] - all behaviors known to be affected in individuals with ADHD [109-111].

The SHR has previously been found to have dysfunctional dopamine dynamics in the striatum and NA core [52], but here we also show evidence for faster dopamine uptake in the cingulate and infralimbic cortices of the medial PFC. These regions are heavily implicated in ADHD $[66,112,113]$ and these data give further evidence for use of the SHR as a model of ADHD. Therapeutics targeting this dysfunction may prove to be useful in the SHR. However, MPH, a DAT blocker, has been investigated and found to not be useful in this model because instead of calming these animals as it does in humans, it increased locomotion in clinically relevant doses [46, 47, 114]. This signifies to us that targeting the NET instead of the DAT, such as with the use of ATX, may provide a more useful option of targeting PFC dopamine dysfunction in the SHR model of ADHD. 


\section{The DRD4 and glutamatergic PFC dysfunction}

The 7-repeat polymorphism of the DRD4 has been implicated in ADHD. Little is known about the neurochemical effects of the DRD4 and thus the DRD4.7. While the DRD4 ${ }^{-/}$mouse is not an exact model for ADHD, it does provide insight to the neurochemistry of DRD4 signaling. In these studies we used in vivo amperometry coupled to a glutamate-selective MEA to measure extracellular levels of glutamate and glutamate clearance in the PFC of DRD4 $4^{+++}$, $\mathrm{DRD}^{+/-}$and DRD4 $4^{--}$mice. We measured a significant increase in extracellular resting levels of glutamate, most prevalent in the cingulate cortex of the medial PFC. We also discovered increased glutamate uptake times that were seen primarily in the prelimbic area. These data support the hypothesis that DRD4 signaling is actively involved in regulating glutamate neurotransmission in the PFC.

We found that lack of DRD4 expression resulted in increased extracellular resting levels of glutamate in the PFC. We are unaware of any extracellular glutamate levels reported from the PFC of anesthetized C57BL $\backslash 6$ mice. Using similar technology, Hascup et al. (2007) found extracellular levels of glutamate in the PFC of awake, freely-moving C57Bl $\backslash 6$ mice to be $3.3 \pm 0.1 \mu \mathrm{M}$ [81]. In this study, we reported approximately $60 \%$ of the extracellular levels recorded from these prior studies in awake animals $(1.42 \pm 0.19 \mu \mathrm{M})$. Urethane anesthesia has been documented to reduce extracellular glutamate levels by $58-80 \%$ in rats and may be contributing to the lower levels of glutamate measured here $[81,115]$. The relative contributions of metabolic and neuronal pools of glutamate to extracellular levels of glutamate and the role of D4 receptors in astrocytic regulation of glutamate still requires investigation. Consequences of increased extracellular levels of glutamate in the PFC would cause alterations in signaling due to increased stimulation of glutamate receptors on astrocytes and presynaptic and postsynaptic neurons. Further studies are required to test these potential changes. There is also indication that the DRD4 is localized to GABA containing interneurons in the PFC [116, 117]. Lack of inhibition resulting from loss of expression of the DRD4 could result in decreased release of GABA. This loss of inhibition could also contribute to increased tonic levels of glutamate in the PFC.

Loss of DRD4 resulted in approximately a $20 \%$ increase in clearance times in DRD4 ${ }^{-/}$mice. The mechanism of the increased clearance time is unknown, but the capacity of this tissue to clear similar amounts of exogenous glutamate was not significantly altered in the DRD4 ${ }^{-/}$ mice, suggesting that transporter expression was unchanged. It is not known whether the measured effects on uptake rate were a direct or indirect effect of DRD4 signaling loss. In all areas of the brain, $80-90 \%$ of glutamate transporters are located on astrocytes [16]. Increased activation of metabotropic glutamate receptors (mGluRs) on astrocytes could potentially affect glutamate clearance in this case, depending on the affinity for glutamate by the mGluRs on astrocytes [118]. Interestingly, there have been reports of the presence of dopamine D2receptors on the astrocytes in the PFC [119]. Prior microdialysis data suggests that extracellular dopamine content and $\mathrm{KCl}$-evoked release of dopamine are lower in the striatum and NAc of DRD4 ${ }^{-/}$mice [120]. Alterations in dopamine neurotransmission in the PFC of these mice may elucidate a special role for the D2 receptor on astrocytes in regulation of dopa- 
mine and glutamate interactions in DRD4 ${ }^{-/}$mice in PFC neurotransmission. Dopamine neurotransmission studies have not been done in these mice, but changes in whole tissue levels of dopamine and dopamine metabolites do not indicate any changes [72].

In multiple publications, the DRD4 has been indicated as having an important role in the cortico-striatal-thalamic loop. Previously, we measured increased extracellular glutamate and slower clearance of glutamate in the striatum, indicating DRD4 regulation in the corticostriatal projections [67]. In these experiments, we measured increased extracellular glutamate levels and slower glutamate clearance in the PFC, representing alterations in glutamatergic projections that primarily originate in the thalamus. Mrzljak et al. (1996) alluded that the DRD4s role in pallido-thalamic pathways may be as a regulator of GABA release [117]. By blocking these receptors, GABA release would be weakened and result in enhanced excitatory pathways beginning in the thalamus. This presents a feed forward situation in which lack of inhibitory modulation of the excitatory pathways of the cortico-striatal-thalamic loop results in increased levels of glutamate in the PFC and the striatum. Although measures of GABA in the pallido-thalamic and striatopallidal projections are necessary, our data continues to support the importance of the DRD4 in the cortico-striatal-thalamic loop, specifically in the regulation of tonic glutamate.

Region specific changes may be due to the concentration of DRD4s and cell types to which they are localized. In a study where bacterial artificial chromosomes expressed enhanced green florescent protein under the transcriptional control of the DRD4, DRD4 localization was found to be high in the orbital, prelimbic, cingulate and rostral agranular potions of the prefrontal cortex [116]. Our study found changes in the cingulate and prelimbic areas, but not the infralimbic area. Localization of DRD4s to interneurons vs. pyramidal neurons may be helpful in elucidating a relationship between altered extracellular glutamate levels in the cingulate cortex in comparison to altered clearance times in the prelimbic area. One caveat of transgenic mice is that compensatory effects may be contributing to the neurochemical effects that we measured. While compensatory effects in the PFC have not been evaluated, alterations in dopamine D1 receptor and NMDA receptor expression were reported in the striatum, nucleus accumbens and hippocampus [67, 120, 121]. Assessment of dopamine, glutamate, and GABA related receptors in the PFC would provide important information necessary for proper evaluation of receptors that could be contributing to the findings reported in this paper and need to be further investigated. Compensatory mechanisms can be indicative of developmental functions that are influenced by the absence of the DRD4 and are important to consider when evaluating glutamate function in the PFC of these knockouts.

\subsection{Future directions in the neuropharmacology of ADHD}

The data presented above in the SHR and DRD4 ${ }^{-/}$rodent models of ADHD provide evidence for dopaminergic and glutamatergic system dysfunction in the PFC. Likewise, it has previously been demonstrated that in the striatum of both models, similar neurotransmitter system dysfunction exists [52, 67]. The DRD4 knockout mouse has also been found to exhibit decreased dopamine levels in the striatum [120]. These data in the DRD4 ${ }^{--}$reveal that the $\mathrm{D}_{4}$ receptor is vital in the regulation of dopamine-glutamate interactions in the striatum and 
PFC. Recent pilot data from our lab (unpublished) reveal that in the SHR model of ADHD, there exists increased resting glutamate levels in the striatum and PFC; however, further experimentation is necessary to verify these results. Glutamate dysfunction in the SHR would then create the possibility that targeting the dopamine-glutamate interaction in this model of ADHD may prove useful as well.

These animal models grant us the ability to investigate neurotransmitter system regulation in vivo, creating a more accurate depiction of the dysfunction in multiple subregions within the PFC. Using these animals, we plan to use common ADHD treatments, such as MPH and ATX, as well as unconventional treatments, such as memantine and deprenyl, to examine the effects of these drugs on the dopamine and glutamate neuronal systems. Our ultimate goal is to discover novel ways to treat ADHD with minimal side-effects and clear long-term safety and efficacy. Avoiding the confounding side effect of abuse potential will be especially advantageous given the difficulties this presents to prescribing stimulants. We believe that targeting the interaction between the dopamine and glutamate systems will provide a new avenue to achieve our goal.

As more and more research is beginning to implicate a dysfunctional glutamate system in $\mathrm{ADHD}$, it's hard to ignore that glutamate may be playing some role in the pathophysiology of ADHD. Although it is too early to know if pharmaceuticals that modulate glutamate will be able to benefit ADHD without their own set of side-effects, it is still our hope that through modification of these interactions, we will be able to better treat individuals with ADHD and greatly improve their quality of life.

\section{Conclusion}

In this chapter, we have reviewed dopamine and glutamate neurotransmission, as well as dopamine-glutamate interactions, specifically relating to ADHD. We have reviewed current literature and have shown the effects of ADHD treatments on these neurotransmitters. We have discussed and detailed two rodent models of ADHD as well as the techniques used to highlight novel data revealing dopamine and glutamate dysfunction in these models of ADHD. Finally, we've examined ways these data will enable the future neuropharmacology of ADHD to move forward. Ultimately, our goal is to find novel therapies targeting dopamine-glutamate interactions to better treat ADHD in individuals of all ages.

\section{Acknowledgements}

This study was supported by USPHS grants MH070840, AG13494, and 5T32AG000242-13, NSF EEC-0310723, and DARPA N66001-09-C- 2080. In addition, the projects described were supported by the National Center for Research Resources, UL1RR033173, and the National Center for Advancing Translational Sciences, UL1TR000117. The content is solely the responsibility of the authors and does not necessarily represent the official views of the NIH. 


\section{Author details}

Erin M. Miller ${ }^{1}$, Theresa C. Thomas², Greg A. Gerhardt ${ }^{1,3,5}$ and Paul E. A. Glaser ${ }^{1,3,4}$

*Address all correspondence to: pglas0@uky.edu

1 Department of Anatomy \& Neurobiology, Center for Microelectrode Technology, University of Kentucky Chandler Medical Center, Lexington, KY, USA

2 Department of Child Health, University of Arizona College of Medicine-Phoenix, Phoenix, AZ, USA

3 Department of Neurology, Department of Psychiatry, University of Kentucky Chandler Medical Center, Lexington, KY, USA

4 Department of Pediatrics, University of Kentucky Chandler Medical Center, Lexington, KY, USA

5 Department of Electrical Engineering, University of Kentucky, Lexington, KY, USA

\section{References}

[1] American Psychiatric Association. Committee on Nomenclature and Statistics. and American Psychiatric Association. Committee on Statistics., Diagnostic and statistical manual: mental disorders. [1st ed. 1952, Washington,: American Psychiatric Assn., Mental Hospital Service. xii, 130 p.

[2] American Psychiatric Association. Committee on Nomenclature and Statistics., Diagnostic and statistical manual of mental disorders. 2d ed. 1968, Washington,. xv, 119 p.

[3] American Psychiatric Association. Task Force on Nomenclature and Statistics. and American Psychiatric Association. Committee on Nomenclature and Statistics., Diagnostic and statistical manual of mental disorders. 3d ed. 1980, Washington: American Psychiatric Assn. 494 p.

[4] Strohl, M.P., Bradley's Benzedrine studies on children with behavioral disorders. Yale J Biol Med, 2011. 84(1): p. 27-33.

[5] Robbins, T.W. and B.J. Sahakian, "Paradoxical" effects of psychomotor stimulant drugs in hyperactive children from the standpoint of behavioural pharmacology. Neuropharmacology, 1979. 18(12): p. 931-50.

[6] Shaywitz, B.A., et al., Paradoxical response to amphetamine in developing rats treated with 6-hydroxydopamine. Nature, 1976. 261(5556): p. 153-5. 
[7] Schultz, W., Reward signaling by dopamine neurons. Neuroscientist, 2001. 7(4): p. 293-302.

[8] Schultz, W., Responses of midbrain dopamine neurons to behavioral trigger stimuli in the monkey. J Neurophysiol, 1986. 56(5): p. 1439-61.

[9] Schultz, W., Predictive reward signal of dopamine neurons. J Neurophysiol, 1998. 80(1): p. 1-27.

[10] Arias-Carrion, O. and E. Poppel, Dopamine, learning, and reward-seeking behavior. Acta Neurobiol Exp (Wars), 2007. 67(4): p. 481-8.

[11] Iversen, L.L., Introduction to neuropsychopharmacology. 2009, New York: Oxford University Press. $x, 557 \mathrm{p}$.

[12] Cass, W.A., et al., Clearance of exogenous dopamine in rat dorsal striatum and nucleus accumbens: role of metabolism and effects of locally applied uptake inhibitors. J Neurochem, 1993. 61(6): p. 2269-78.

[13] Carrey, N., et al., Glutamatergic changes with treatment in attention deficit hyperactivity disorder: a preliminary case series. J Child Adolesc Psychopharmacol, 2002. 12(4): p. 331-6.

[14] Moore, C.M., et al., Differences in brain chemistry in children and adolescents with attention deficit hyperactivity disorder with and without comorbid bipolar disorder: a proton magnetic resonance spectroscopy study. Am J Psychiatry, 2006. 163(2): p. 316-8.

[15] Moore, C.M., et al., Glutamine and glutamate levels in children and adolescents with bipolar disorder: a 4.0-T proton magnetic resonance spectroscopy study of the anterior cingulate cortex. J Am Acad Child Adolesc Psychiatry, 2007. 46(4): p. 524-34.

[16] Danbolt, N.C., Glutamate uptake. Prog Neurobiol, 2001. 65(1): p. 1-105.

[17] Warton, F.L., F.M. Howells, and V.A. Russell, Increased glutamate-stimulated release of dopamine in substantia nigra of a rat model for attention-deficit/hyperactivity disorder-lack of effect of methylphenidate. Metab Brain Dis, 2009. 24(4): p. 599-613.

[18] Martinez-Fong, D., et al., NMDA receptor mediates dopamine release in the striatum of unanesthetized rats as measured by brain microdialysis. Brain Res, 1992. 595(2): p. 309-15.

[19] Kotecha, S.A., et al., A D2 class dopamine receptor transactivates a receptor tyrosine kinase to inhibit NMDA receptor transmission. Neuron, 2002. 35(6): p. 1111-22.

[20] Yuen, E.Y., et al., Regulation of AMPA receptor channels and synaptic plasticity by cofilin phosphatase Slingshot in cortical neurons. J Physiol, 2010. 588(Pt 13): p. 2361-71.

[21] Carboni, E., et al., Amphetamine, cocaine, phencyclidine and nomifensine increase extracellular dopamine concentrations preferentially in the nucleus accumbens of freely moving rats. Neuroscience, 1989. 28(3): p. 653-61. 
[22] Kahlig, K.M. and A. Galli, Regulation of dopamine transporter function and plasma membrane expression by dopamine, amphetamine, and cocaine. Eur J Pharmacol, 2003. 479(1-3): p. $153-8$.

[23] Kuczenski, R. and D.S. Segal, Effects of methylphenidate on extracellular dopamine, serotonin, and norepinephrine: comparison with amphetamine. J Neurochem, 1997. 68(5): p. 2032-7.

[24] Kuczenski, R. and D.S. Segal, Locomotor effects of acute and repeated threshold doses of amphetamine and methylphenidate: relative roles of dopamine and norepinephrine. J Pharmacol Exp Ther, 2001. 296(3): p. 876-83.

[25] Gerasimov, M.R., et al., Synergistic interactions between nicotine and cocaine or methylphenidate depend on the dose of dopamine transporter inhibitor. Synapse, 2000. 38(4): p. 432-7.

[26] Volkow, N.D., et al., Therapeutic doses of oral methylphenidate significantly increase extracellular dopamine in the human brain. J Neurosci, 2001. 21(2): p. RC121.

[27] Huff, J.K. and M.I. Davies, Microdialysis monitoring of methylphenidate in blood and brain correlated with changes in dopamine and rat activity. J Pharm Biomed Anal, 2002. 29(5): p. 767-77.

[28] Gerasimov, M.R., et al., Comparison between intraperitoneal and oral methylphenidate administration: A microdialysis and locomotor activity study. J Pharmacol Exp Ther, 2000. 295(1): p. 51-7.

[29] Marsteller, D.A., et al., Acute handling stress modulates methylphenidate-induced catecholamine overflow in the medial prefrontal cortex. Neuropsychopharmacology, 2002. 27(2): p. $163-70$.

[30] Newman, L.A., J. Darling, and J. McGaughy, Atomoxetine reverses attentional deficits produced by noradrenergic deafferentation of medial prefrontal cortex. Psychopharmacology (Berl), 2008. 200(1): p. 39-50.

[31] Bymaster, F.P., et al., Atomoxetine increases extracellular levels of norepinephrine and dopamine in prefrontal cortex of rat: a potential mechanism for efficacy in attention deficit/hyperactivity disorder. Neuropsychopharmacology, 2002. 27(5): p. 699-711.

[32] Swanson, C.J., et al., Effect of the attention deficit/hyperactivity disorder drug atomoxetine on extracellular concentrations of norepinephrine and dopamine in several brain regions of the rat. Neuropharmacology, 2006. 50(6): p. 755-60.

[33] Michelson, D., et al., Atomoxetine in the treatment of children and adolescents with attention-deficit/hyperactivity disorder: a randomized, placebo-controlled, dose-response study. Pediatrics, 2001. 108(5): p. E83.

[34] Michelson, D., et al., Atomoxetine in adults with ADHD: two randomized, placebo-controlled studies. Biol Psychiatry, 2003. 53(2): p. 112-20. 
[35] Adler, L.A., et al., Long-term, open-label study of the safety and efficacy of atomoxetine in adults with attention-deficit/hyperactivity disorder: an interim analysis. J Clin Psychiatry, 2005. 66(3): p. 294-9.

[36] Adler, L.A., et al., Long-term, open-label safety and efficacy of atomoxetine in adults with ADHD: final report of a 4-year study. J Atten Disord, 2008. 12(3): p. 248-53.

[37] Ludolph, A.G., et al., Atomoxetine acts as an NMDA receptor blocker in clinically relevant concentrations. Br J Pharmacol, 2010. 160(2): p. 283-91.

[38] Hammerness, P., et al., Brain biochemical effects of methylphenidate treatment using proton magnetic spectroscopy in youth with attention-deficit hyperactivity disorder: a controlled pilot study. CNS Neurosci Ther, 2012. 18(1): p. 34-40.

[39] Wiguna, T., et al., Effect of 12-week administration of 20-mg long-acting methylphenidate on $\mathrm{Glu} / \mathrm{Cr}, \mathrm{NAA} / \mathrm{Cr}, \mathrm{Cho} / \mathrm{Cr}$, and $\mathrm{mI} / \mathrm{Cr}$ ratios in the prefrontal cortices of school-age children in Indonesia: a study using $1 \mathrm{H}$ magnetic resonance spectroscopy (MRS). Clin Neuropharmacol, 2012. 35(2): p. 81-5.

[40] Fumagalli, F., et al., Sub-chronic exposure to atomoxetine up-regulates BDNF expression and signalling in the brain of adolescent spontaneously hypertensive rats: comparison with methylphenidate. Pharmacol Res, 2010. 62(6): p. 523-9.

[41] Rogawski, M.A. and G.L. Wenk, The neuropharmacological basis for the use of memantine in the treatment of Alzheimer's disease. CNS Drug Rev, 2003. 9(3): p. 275-308.

[42] Seeman, P., C. Caruso, and M. Lasaga, Memantine agonist action at dopamine D2High receptors. Synapse, 2008. 62(2): p. 149-53.

[43] Surman, C.B., et al., A pilot open label prospective study of memantine monotherapy in adults with ADHD. World J Biol Psychiatry, 2012.

[44] Jankovic, J., Deprenyl in attention deficit associated with Tourette's syndrome. Arch Neurol, 1993. 50(3): p. 286-8.

[45] Feigin, A., et al., A controlled trial of deprenyl in children with Tourette's syndrome and attention deficit hyperactivity disorder. Neurology, 1996. 46(4): p. 965-8.

[46] Sagvolden, T., Behavioral validation of the spontaneously hypertensive rat (SHR) as an animal model of attention-deficit/hyperactivity disorder (AD/HD). Neurosci Biobehav Rev, 2000. 24(1): p. 31-9.

[47] Sagvolden, T., et al., The spontaneously hypertensive rat (SHR) as an animal model of childhood hyperactivity (ADHD): changed reactivity to reinforcers and to psychomotor stimulants. Behav Neural Biol, 1992. 58(2): p. 103-12.

[48] Sagvolden, T., E.D. Hendley, and S. Knardahl, Behavior of hypertensive and hyperactive rat strains: hyperactivity is not unitarily determined. Physiol Behav, 1992. 52(1): p. 49-57. 
[49] Wultz, B. and T. Sagvolden, The hyperactive spontaneously hypertensive rat learns to sit still, but not to stop bursts of responses with short interresponse times. Behav Genet, 1992. 22(4): p. 415-33.

[50] Knardahl, S. and T. Sagvolden, Open-field behavior of spontaneously hypertensive rats. Behav Neural Biol, 1979. 27(2): p. 187-200.

[51] Russell, V., et al., Differences between electrically-, ritalin- and D-amphetamine-stimulated release of [3H]dopamine from brain slices suggest impaired vesicular storage of dopamine in an animal model of Attention-Deficit Hyperactivity Disorder. Behav Brain Res, 1998. 94(1): p. $163-71$.

[52] Miller, E.M., et al., The spontaneously hypertensive and Wistar Kyoto rat models of ADHD exhibit sub-regional differences in dopamine release and uptake in the striatum and nucleus accumbens. Neuropharmacology, 2012. 63(8): p. 1327-1334.

[53] Myers, M.M., S.R. Whittemore, and E.D. Hendley, Changes in catecholamine neuronal uptake and receptor binding in the brains of spontaneously hypertensive rats (SHR). Brain Res, 1981. 220(2): p. 325-38.

[54] Li, Q., et al., The usefulness of the spontaneously hypertensive rat to model attention-deficit/ hyperactivity disorder (ADHD) may be explained by the differential expression of dopaminerelated genes in the brain. Neurochem Int, 2007. 50(6): p. 848-57.

[55] Russell, V.A., Increased AMPA receptor function in slices containing the prefrontal cortex of spontaneously hypertensive rats. Metab Brain Dis, 2001. 16(3-4): p. 143-9.

[56] Russell, V.A., Hypodopaminergic and hypernoradrenergic activity in prefrontal cortex slices of an animal model for attention-deficit hyperactivity disorder--the spontaneously hypertensive rat. Behav Brain Res, 2002. 130(1-2): p. 191-6.

[57] Asghari, V., et al., Modulation of intracellular cyclic AMP levels by different human dopamine D4 receptor variants. J Neurochem, 1995. 65(3): p. 1157-65.

[58] Faraone, S.V., et al., Meta-analysis of the association between the 7-repeat allele of the dopamine $D(4)$ receptor gene and attention deficit hyperactivity disorder. Am J Psychiatry, 2001. 158(7): p. 1052-7.

[59] Sunohara, G.A., et al., Linkage of the dopamine D4 receptor gene and attention-deficit/ hyperactivity disorder. J Am Acad Child Adolesc Psychiatry, 2000. 39(12): p. 1537-42.

[60] Swanson, J., et al., Attention deficit/hyperactivity disorder children with a 7-repeat allele of the dopamine receptor D4 gene have extreme behavior but normal performance on critical neuropsychological tests of attention. Proc Natl Acad Sci U S A, 2000. 97(9): p. 4754-9.

[61] Todd, R.D., et al., Collaborative analysis of DRD4 and DAT genotypes in population-defined ADHD subtypes. J Child Psychol Psychiatry, 2005. 46(10): p. 1067-73. 
[62] Shaw, P., et al., Polymorphisms of the dopamine D4 receptor, clinical outcome, and cortical structure in attention-deficit/hyperactivity disorder. Arch Gen Psychiatry, 2007. 64(8): p. 921-31.

[63] Ariano, M.A., et al., Coexpression of striatal dopamine receptor subtypes and excitatory amino acid subunits. Synapse, 1997. 26(4): p. 400-14.

[64] Ariano, M.A., et al., Cellular distribution of the rat D4 dopamine receptor protein in the CNS using anti-receptor antisera. Brain Res, 1997. 752(1-2): p. 26-34.

[65] Faraone, S.V., et al., Familial subtypes of attention deficit hyperactivity disorder: a 4-year follow-up study of children from antisocial-ADHD families. J Child Psychol Psychiatry, 1998. 39(7): p. 1045-53.

[66] Arnsten, A.F. and B.M. Li, Neurobiology of executive functions: catecholamine influences on prefrontal cortical functions. Biol Psychiatry, 2005. 57(11): p. 1377-84.

[67] Thomas, T.C., et al., Decreased dopamine D4 receptor expression increases extracellular glutamate and alters its regulation in mouse striatum. Neuropsychopharmacology, 2009. 34(2): p. 436-45.

[68] Rubinstein, M., et al., Mice lacking dopamine D4 receptors are supersensitive to ethanol, cocaine, and methamphetamine. Cell, 1997. 90(6): p. 991-1001.

[69] Falzone, T.L., et al., Absence of dopamine D4 receptors results in enhanced reactivity to unconditioned, but not conditioned, fear. Eur J Neurosci, 2002. 15(1): p. 158-64.

[70] Dulawa, S.C., et al., Dopamine D4 receptor-knock-out mice exhibit reduced exploration of novel stimuli. J Neurosci, 1999. 19(21): p. 9550-6.

[71] Kruzich, P.J., K.L. Suchland, and D.K. Grandy, Dopamine D4 receptor-deficient mice, congenic on the C57BL/6J background, are hypersensitive to amphetamine. Synapse, 2004. 53(2): p. 131-9.

[72] Rubinstein, M., et al., Dopamine D4 receptor-deficient mice display cortical hyperexcitability. J Neurosci, 2001. 21(11): p. 3756-63.

[73] Hinzman, J.M., et al., Disruptions in the regulation of extracellular glutamate by neurons and glia in the rat striatum two days after diffuse brain injury. J Neurotrauma, 2012. 29(6): p. 1197-208.

[74] Littrell, O.M., et al., Enhanced dopamine transporter activity in middle-aged Gdnf heterozygous mice. Neurobiol Aging, 2012.

[75] Paxinos, G. and C. Watson, The rat brain in stereotaxic coordinates. 6th ed. 2009, Amsterdam ; Boston ;: Academic Press/Elsevier.

[76] Cass, W.A., et al., Differences in dopamine clearance and diffusion in rat striatum and nucleus accumbens following systemic cocaine administration. J Neurochem, 1992. 59(1): p. 259-66. 
[77] Friedemann, M.N. and G.A. Gerhardt, Regional effects of aging on dopaminergic function in the Fischer-344 rat. Neurobiol Aging, 1992. 13(2): p. 325-32.

[78] Hinzman, J.M., et al., Diffuse brain injury elevates tonic glutamate levels and potassiumevoked glutamate release in discrete brain regions at two days post-injury: an enzyme-based microelectrode array study. J Neurotrauma, 2010. 27(5): p. 889-99.

[79] Thomas, T.C., et al., Hypersensitive glutamate signaling correlates with the development of late-onset behavioral morbidity in diffuse brain-injured circuitry. J Neurotrauma, 2012. 29(2): p. 187-200.

[80] Burmeister, J.J. and G.A. Gerhardt, Self-referencing ceramic-based multisite microelectrodes for the detection and elimination of interferences from the measurement of L-glutamate and other analytes. Anal Chem, 2001. 73(5): p. 1037-42.

[81] Hascup, K.N., et al., Second-by-Second Measures of L-Glutamate and Other Neurotransmitters Using Enzyme-Based Microelectrode Arrays. 2007.

[82] Franklin, K.B.J. and G. Paxinos, The mouse brain in stereotaxic coordinates. 1997, San Diego: Academic Press. xxii p., 186 p. of plates.

[83] Hebert, M.A., et al., Age-related reductions in [3H]WIN 35,428 binding to the dopamine transporter in nigrostriatal and mesolimbic brain regions of the fischer 344 rat. J Pharmacol Exp Ther, 1999. 288(3): p. 1334-9.

[84] Levy, F., The dopamine theory of attention deficit hyperactivity disorder (ADHD). Aust N Z J Psychiatry, 1991. 25(2): p. 277-83.

[85] Linthorst, A.C., et al., Electrically stimulated [3H]dopamine and [14C]acetylcholine release from nucleus caudatus slices: differences between spontaneously hypertensive rats and Wistar-Kyoto rats. Brain Res, 1990. 509(2): p. 266-72.

[86] Linthorst, A.C., et al., Effect of the dopamine D2 receptor agonist quinpirole on the in vivo release of dopamine in the caudate nucleus of hypertensive rats. Eur J Pharmacol, 1991. 201(2-3): p. 125-33.

[87] Versteeg, D.H., et al., Regional concentrations of noradrenaline and dopamine in rat brain. Brain Res, 1976. 113(3): p. 563-74.

[88] Ferguson, S.A., B.J. Gough, and A.M. Cada, In vivo basal and amphetamine-induced striatal dopamine and metabolite levels are similar in the spontaneously hypertensive, WistarKyoto and Sprague-Dawley male rats. Physiol Behav, 2003. 80(1): p. 109-14.

[89] Obrenovitch, T.P., et al., Excitotoxicity in neurological disorders--the glutamate paradox. Int J Dev Neurosci, 2000. 18(2-3): p. 281-7.

[90] Borland, L.M., et al., Voltammetric study of extracellular dopamine near microdialysis probes acutely implanted in the striatum of the anesthetized rat. J Neurosci Methods, 2005. 146(2): p. 149-58. 
[91] Wang, Y. and A.C. Michael, Microdialysis probes alter presynaptic regulation of dopamine terminals in rat striatum. J Neurosci Methods, 2012. 208(1): p. 34-9.

[92] Gerhardt, G.A., G.M. Rose, and B.J. Hoffer, Release of monoamines from striatum of rat and mouse evoked by local application of potassium: evaluation of a new in vivo electrochemical technique. J Neurochem, 1986. 46(3): p. 842-50.

[93] Leo, D., et al., Altered midbrain dopaminergic neurotransmission during development in an animal model of ADHD. Neurosci Biobehav Rev, 2003. 27(7): p. 661-9.

[94] Roessner, V., et al., Methylphenidate normalizes elevated dopamine transporter densities in an animal model of the attention-deficit/hyperactivity disorder combined type, but not to the same extent in one of the attention-deficit/hyperactivity disorder inattentive type. Neuroscience, 2010. 167(4): p. 1183-91.

[95] Simchon, Y., A. Weizman, and M. Rehavi, The effect of chronic methylphenidate administration on presynaptic dopaminergic parameters in a rat model for ADHD. Eur Neuropsychopharmacol, 2010. 20(10): p. 714-20.

[96] Viggiano, D., D. Vallone, and A. Sadile, Dysfunctions in dopamine systems and ADHD: evidence from animals and modeling. Neural Plast, 2004. 11(1-2): p. 97-114.

[97] Watanabe, Y., et al., Brain dopamine transporter in spontaneously hypertensive rats. J Nucl Med, 1997. 38(3): p. 470-4.

[98] Womersley, J.S., et al., Maternal separation affects dopamine transporter function in the Spontaneously Hypertensive Rat: An in vivo electrochemical study. Behav Brain Funct, 2011. 7: p. 49.

[99] Moron, J.A., et al., Dopamine uptake through the norepinephrine transporter in brain regions with low levels of the dopamine transporter: evidence from knock-out mouse lines. J Neurosci, 2002. 22(2): p. 389-95.

[100] El Ayadi, A., I. Afailal, and M. Errami, Effects of voltage-sensitive calcium channel blockers on extracellular dopamine levels in rat striatum. Metab Brain Dis, 2001. 16(3-4): p. 121-31.

[101] Hoffman, A.F., et al., Voltage-dependency of the dopamine transporter in the rat substantia nigra. Neurosci Lett, 1999. 260(2): p. 105-8.

[102] Kandasamy, S.B., Possible involvement of L-type voltage-gated calcium channels in release of dopamine in the striatum of irradiated rats. Radiat Res, 2000. 154(1): p. 39-43.

[103] Reith, M.E., et al., Effect of metaphit on dopaminergic neurotransmission in rat striatal slices: involvement of the dopamine transporter and voltage-dependent sodium channel. J Pharmacol Exp Ther, 1991. 259(3): p. 1188-96.

[104] Zahniser, N.R., et al., Voltage-dependency of the dopamine transporter in rat brain. Adv Pharmacol, 1998. 42: p. 195-8. 
[105] Granziera, C., et al., In-vivo magnetic resonance imaging of the structural core of the Papez circuit in humans. Neuroreport, 2011. 22(5): p. 227-31.

[106] Adey, W.R., An experimental study of the hippocampal connexions of the cingulate cortex in the rabbit. Brain, 1951. 74(2): p. 233-47.

[107] Adey, W.R. and M. Meyer, An experimental study of hippocampal afferent pathways from prefrontal and cingulate areas in the monkey. J Anat, 1952. 86(1): p. 58-74.

[108] Dalley, J.W., R.N. Cardinal, and T.W. Robbins, Prefrontal executive and cognitive functions in rodents: neural and neurochemical substrates. Neurosci Biobehav Rev, 2004. 28(7): p. 771-84.

[109] Mehta, M.A., I.M. Goodyer, and B.J. Sahakian, Methylphenidate improves working memory and set-shifting in AD/HD: relationships to baseline memory capacity. J Child Psychol Psychiatry, 2004. 45(2): p. 293-305.

[110] Klimkeit, E.I., et al., Motor preparation, motor execution, attention, and executive functions in attention deficit/hyperactivity disorder (ADHD). Child Neuropsychol, 2005. 11(2): p. 153-73.

[111] Krusch, D.A., et al., Methylphenidate slows reactions of children with attention deficit disorder during and after an error. J Abnorm Child Psychol, 1996. 24(5): p. 633-50.

[112] Arnsten, A.F. and A.G. Dudley, Methylphenidate improves prefrontal cortical cognitive function through alpha2 adrenoceptor and dopamine D1 receptor actions: Relevance to therapeutic effects in Attention Deficit Hyperactivity Disorder. Behav Brain Funct, 2005. 1(1): p. 2.

[113] Arnsten, A.F., Toward a new understanding of attention-deficit hyperactivity disorder pathophysiology: an important role for prefrontal cortex dysfunction. CNS Drugs, 2009. 23 Suppl 1: p. 33-41.

[114] Sagvolden, T. and E.B. Johansen, Rat Models of ADHD. Curr Top Behav Neurosci, 2011.

[115] Day, B.K., et al., Microelectrode array studies of basal and potassium-evoked release of Lglutamate in the anesthetized rat brain. J Neurochem, 2006. 96(6): p. 1626-35.

[116] Noain, D., et al., Identification of brain neurons expressing the dopamine D4 receptor gene using BAC transgenic mice. Eur J Neurosci, 2006. 24(9): p. 2429-38.

[117] Mrzljak, L., et al., Localization of dopamine D4 receptors in GABAergic neurons of the primate brain. Nature, 1996. 381(6579): p. 245-8.

[118] Schoepp, D.D., Unveiling the functions of presynaptic metabotropic glutamate receptors in the central nervous system. J Pharmacol Exp Ther, 2001. 299(1): p. 12-20.

[119] Khan, Z.U., et al., An astroglia-linked dopamine D2-receptor action in prefrontal cortex. Proc Natl Acad Sci U S A, 2001. 98(4): p. 1964-9. 
[120] Thomas, T.C., et al., Dopamine D4 receptor knockout mice exhibit neurochemical changes consistent with decreased dopamine release. J Neurosci Methods, 2007. 166(2): p. 306-14.

[121] Gan, L., et al., Enhanced expression of dopamine $D(1)$ and glutamate NMDA receptors in dopamine D(4) receptor knockout mice. J Mol Neurosci, 2004. 22(3): p. 167-78. 